Automobiltechnische Bibliothek Band XIII

Die elektrische Ausrüstung des Kraftfahrzeuges

Zweiter Teil 


\title{
Automobiltechnische Bibliothek
}

\section{Die Automobiltechnik in Einzeldarstellungen}

Band XIII

\section{Die elektrische Ausrüstung des Kraftfahrzeuges}

\author{
Herausgegeben von \\ Dr. Friedrich Trautmann
}

\begin{abstract}
I. Teil: Zündung von Erich Klaiber
II. Teil: Lichtmaschine und Batterie

von Emil Blaich, Walter Härlin, Karl Hoyer und Friedrich Trautmann

III. Teil: Stromverbraucher

von Walter Härlin, Eugen Kienle, Johannes Rebentisch und Karl Volk
\end{abstract}

Technischer Verlag Herbert Cram / Berlin W 35 


\title{
Die elektrische Ausrüstung des Kraftfahrzeuges \\ Zweiter Teil
}

\section{Lichtmaschine und Batterie}

Von

\author{
Dr. Emil Blaich, Walter Härlin, Karl Hoyer \\ und Dr. Friedrich Trautmann
}

Zweite, völlig neubearbeitete Auf lage

Mit 193 Abbildungen

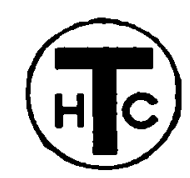

19562

Technischer Verlag Herbert Cram / Berlin W 35 
Druck: Achilles u. Schwulera (Pächter Georg Krautwald), Berlin SW 61 